\title{
PRESCRIBING PATTERN OF NSAIDS IN ORTHOPEDIC DEPARTMENT OF DHAKA MEDICAL COLLEGE HOSPITAL
}

\author{
RAHMAN KA ${ }^{1}$, KAMAL AHMM ${ }^{2}$, AKHTER $\mathrm{S}^{3}$, KHATUN K ${ }^{4}$, AFROZ R ${ }^{5}$, AKTHER T ${ }^{6}$
}

\begin{abstract}
Context : Drug therapy is the most commonly used method in disease treatment in general practice. The pattern of drug prescription are often inappropriate and need for registration of these patterns is essentian in an effort to improve prescribing standard. Nonsteroidal antiinflammatory drugs (NSAIDs) are a drug class that groups together drugs that provide analgesic (pain-killing) and antipyretic (fever-reliefing) effects, and, in higher doses, anti-inflammatory effects. Non steroidal anti inflammatory drugs are the most common drugs prescribed in the world over specially in the orthopedic department. The study of prescribing pattern of NSAIDs in the orthopedic department was conducted to monitor, evaluate and if necessary suggest modification in the prescribing behavior of the medical practitioner to make it rational and cost effective.
\end{abstract}

Material and Methods: The present study was performed on 300 (Three hundred) prescriptions from both admitted and outpatients (OPD) of the orthopedic department of Dhaka Medical College Hospital, Dhaka. The check list type of data was collected with prior permission from the concern department and the authority. The study was cross sectional analytical type and was conducted in the department of Pharmacology, Dhaka Medical College, Dhaka, from July 2010 to June 2011.

Result : In case of OPD patients most common NSAIDs prescribed to the patients were aceclofenac (44.7\%); followed by diclofenac (23.3\%). Other NSAIDs were naproxen, ketorolac and ibuprofen $8 \%, 15.3 \%$ and $5.4 \%$ respectively. In case of admitted patients most common NSAIDs prescribed to the patients were ketorolac (54.7\%) followed by diclofenac (24.0\%).

Conclusion: Non steroidal anti inflammatory drugs were the main prescription drug for both indoor and outdoor patients in the orthopedic department. Aceclofenac in outdoor and ketorolac in indoor were the most common NSAIDs drug used.

Key words : Prescribing pattern, NSAID drug, orthopedic department.

J Dhaka Med Coll. 2016; 25(1): 58-60

\section{Introduction:}

Prescription writing is a science and art, as because it conveys the message from the prescriber to the patient. A prescription by a doctor is taken as a reflection of the physician's attitude to the disease and the role of drug in the treatment ${ }^{1}$. Periodic evaluation of drug utilization patterns need to be done to enable suitable modification in prescription of drugs to increase the therapeutic benefits and decrease the adverse effects ${ }^{2}$. Drug therapy is the most commonly used method in disease treatment in general drug therapy. However the pattern of drug prescription are often inappropriate and need for registration for these pattern is essential in an effort to improve prescribing standard ${ }^{3}$. The study of prescribing pattern seeks to monitor, evaluate and if necessary suggest modification in the prescribing behavior of medical practitioner to

1. Dr. Kazi Afzalur Rahman, Associate Professor, Department of Pharmacology. Dhaka Medical College, Dhaka.

2. Dr. A.H.M. Mostafa Kamal, Assistant Professor, Department of Anatomy, Dhaka Medical College, Dhaka.

3. Dr. Sanjida Akhter, Assistant Professor, Department of Forensic Medicine, Green Life Medical College, Dhaka.

4. Dr. Khadeza Khatun, Assistant Professor, Department of Microbiology. Sir Salimullah Medical College, Dhaka.

5. Dr. Rumana Afroz, Assistant Professor, Department of Pharmacology. Dhaka Medical College, Dhaka.

6. Dr. Tahmina Akther, Medical Officer, Department of Virology, Bangabandhu Sheikh Mujib Medical University Correspondence : Dr. Kazi Afzalur Rahman, Associate Professor, Department of Pharmacology, Dhaka Medical College, Dhaka, Cell Phone: +8801715135212, E-mail: kaziafzalrahman@yahoo.com

Received: 15 March 2016

Accepted: 20 March 2016 
make care rational and cost effective ${ }^{4}$. The impact of inappropriate prescription of drug also leads to an increase in the incidence of adverse drug events and emergence of drug resistance ${ }^{5}$.

The NSAIDs are grouped in several chemical classes. This chemical diversity yields a broad range of pharmacokinetic characteristics. Although there are many differences in the kinetic of NSAIDs, they have some general properties in common. Most of the NSAIDs are highly metabolized, some by phase I followed by phase II mechanism and others by direct glucuronidation (phase II) alone ${ }^{6}$.

Non steroidal anti inflammatory drugs are the most common drugs prescribed the world over. However, they have many adverse effects, especially gastrointestinal toxicity, which is the reason for their frequent co-prescription with gastroprotective agents ${ }^{7}$. It has been observed in many countries that the main thrist of prescribing drugs has shifted from the list of essential drugs. The prescribing skill of the prescriber can be assed by conducting periodic evaluation ${ }^{8}$.

Inappropriate prescriptions increase the cost of medical treatment and increases morbidity and mortality. So, the present study was conducted to evaluate the prescribing pattern of orthopedic department of Dhaka Medical College Hospitals.

\section{Materials and methods:}

The present study was performed on 300 (Three hundred) prescriptions of both sexes from both admitted and outpatients (OPD) of the orthopedic department of Dhaka Medical College Hospital, Dhaka. Among them 150 (One hundred and fifty) prescriptions were included from patients attended in outpatient department and 150 (One hundred and fifty) prescriptions were included patients admitted in the hospital. The check list type of data was collected with prior permission from the concern department and the authority. The study was cross sectional analytical type and was conducted in the department of Pharmacology, Dhaka Medical College, Dhaka, from July 2010 to June 2011. Data were collected and analyzed by SPSS 16.1.

\section{Ethical Clearance :}

This study was approved by the Ethical Review Committee of Dhaka Medical College, Dhaka.

\section{Results :}

Table-I shows the distribution of NSAIDs prescribed to the patient attended at OPD and admitted in the Dhaka Medical College Hospital. In case of OPD patients most common NSAIDs prescribed to the patients were aceclofenac $(44.7 \%)$; followed by diclofenac $(23.3 \%)$. Other NSAIDs were naproxen, ketorolac and ibuprofen $8 \%, 15.3 \%$ and $5.4 \%$ respectively. In case of admitted patients (Table-I, Fig-1) most common NSAIDs prescribed to the patients were ketorolac $(54.7 \%)$ followed by diclofenac $(24.0 \%)$. Other NSAIDs naproxen, ketorolac and ibuprofen $2.7 \%, 8.0 \%$ and $9.3 \%$ respectively.

Table-I

Distribution of type of NSAIDs prescribed to the OPD $(n=150)$ and admitted $(n=150)$ patients.

\begin{tabular}{lcccc}
\hline Name of Drug & \multicolumn{2}{c}{ OPD Patients $(\mathrm{n}=150)$} & \multicolumn{2}{c}{ Admitted Patients $(\mathrm{n}=150)$} \\
& $\begin{array}{c}\text { Frequency } \\
\mathrm{n}\end{array}$ & $\begin{array}{c}\text { Percentage } \\
(\%)\end{array}$ & $\begin{array}{c}\text { Frequency } \\
\text { Percentage } \\
(\%)\end{array}$ \\
\hline Diclofenac & 35 & 23.3 & 36 & 24 \\
Aceclofenac & 67 & 44.7 & 12 & 8 \\
Naproxen & 12 & 8 & 4 & 2.7 \\
Ketorolac & 23 & 15.3 & 82 & 54.7 \\
Ibuprofen & 8 & 5.4 & 14 & 9.3 \\
Others & 5 & 3.3 & 2 & 1.3 \\
\hline Total & 150 & $100 \%$ & 150 & $100 \%$ \\
\hline
\end{tabular}




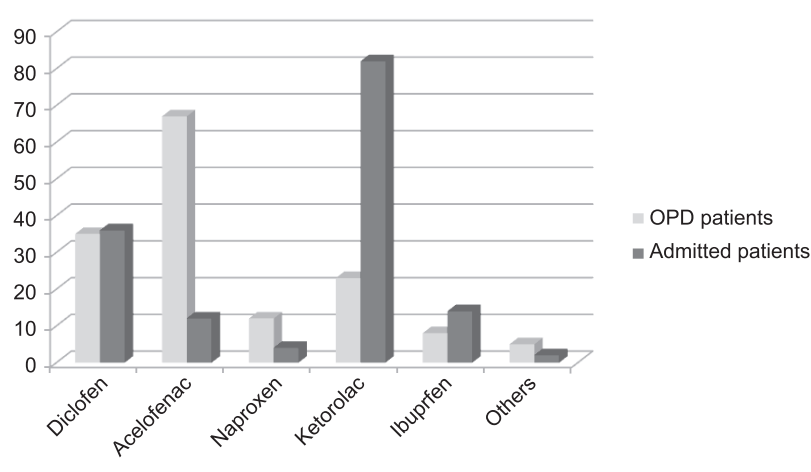

Fig.--1 : Distribution of type of NSAIDs prescribed to the OPD $(n=150)$ and admitted $(n=150)$ patients.

\section{Discussion :}

The present study was performed on 300 (Three hundred) prescriptions of both sexes from both indoor and outdoor patients of the orthopedic department of Dhaka Medical College Hospital, Dhaka. Among them 150 (One hundred and fifty) prescriptions were included from patients attended in outpatient department and 150 (One hundred and fifty) prescriptions were included patients admitted in the hospital. In case of OPD patients most common NSAIDs prescribed to the patients were aceclofenac (44.7\%); followed by diclofenac (23.3\%). Other NSAIDs were naproxen, ketorolac and ibuprofen $8 \%, 15.3 \%$ and $5.4 \%$ respectively (Table-I, Fig1). In the year 2003 Sweileh studied a pharmotherapeutic analysis of NSAIDs prescription for patients attending rheumatology and orthopedic clinic in Gaza. In his study three most commonly prescribed NSAIDs were diclofenac $(40 \%)$, indomethacin $(30 \%)$ and naproxen $(28 \%)$. He also found gastroprotective co-therapy strategies are being under utilized ${ }^{9}$.

In the present study (Table-I, Fig-1) the most common NSAIDs prescribed to the admitted patients were ketorolac (54.7\%) followed by diclofenac $(24.0 \%)$. Other NSAIDs naproxen, ketorolac and ibuprofen $2.7 \%, 8.0 \%$ and $9.3 \%$ respectively. In a study on orthopedic patients Gor and Saksena ${ }^{10}$ (2011) found that diclofenac $(65 \%)$ was the highest prescribed drug, followed by nimesulide $(10 \%)$, ibuprofen $(6 \%)$, piroxicam $(5 \%)$, etoricoxib $(2 \%)$ and others $(12 \%)$.

\section{Conclusion :}

Inappropriate prescriptions increase the cost of medical treatment and increases morbidity and mortality. Non steroidal anti inflammatory drugs are the most common drugs prescribed the world over. However, they have many adverse effects, especially gastrointestinal toxicity, which is the reason for their frequent co-prescription with gastroprotective agents. In the present study showed NSAIDs were the main prescription drug for both indoor and outdoor patients in the orthopedic department. Aceclofenac (44.7\%) in outdoor and ketorolac $(54.7 \%)$ in admitted patients were the most common NSAIDs drug used.

\section{References :}

1. Mishra KP, Prabhu M, SHanker PR, Palaian S, Bhandari RB and Butt DA. Study on rational drug prescribing and dispensing in out patients in a tertiary care teaching hospital in western Nepal. Univ Med J 2006; 4 : 436-43

2. Singh KUS,Pandey RC. Evaluation of prescribing pattern of doctors for rational drug therapy. Indian Journal of Pharmacology 1998; 30 : 40-6

3. Biswas NR et al. Pattern of Prescriptions and Drugs Use in Two Tertiary Hospitals in Delhi. Indian $\mathrm{J}$ of Physiology and Pharmacology 2000; 44(1) : 109-12.

4. Shrishyli MV, Krishnamurthy M, Naga RMA, Andrade CM, Venkatraman BV. Prescription Audit in an Indian Hospital Setting. Indian $\mathrm{J}$ of Pharmacology 1994; 26 : 23-9.

5. Hogerzeil HV. Promoting Rational Prescribing : an International Perspective. $\mathrm{Br} \mathrm{J}$ Clin Pharmacol 1995; 39(1) : 1-6.

6. Katzung Bg. Non Steroidal Anti Inflammatory Drugs. Basic and Clinical Pharmacology, $10^{\text {th }}$ edition. McGraw Hill Lange, San Francisco 2006. P. 321-389.

7. Raghavendra B et al. trends in Prescribing Gastroprotective agents with Non Steroidal Antiinflammatory Drugs in an Orthopedic Outpatient Unit of a Tertiary Care Hospital. J of Clinical and Diagnostic Research 2009 ; (3) : 1553-56

8. Shanker C, Das B. Prescribing Trends in a Teaching Hospital in Western Nepal. JNGMC 2002; $2: 4-7$.

9. Sweileh WM. Pharmacotherapeutic Analysis of NSAIds Prescribed at Rheumatology/ Orthopedic Clinics. J Al Azhar University- Gaza 2003 ; 6(2) : 47-56.

10. Gor AP, Saksena M. Adverse Drug Reactions of NSAIDs in Orthopedic Patient. J Pharmacol Pharmacother 2011; 2 : 26-9. 